Syntax Literate: Jurnal Ilmiah Indonesia p-ISSN: 2541-0849 e-ISSN: 2548-1398

Vol. 6, No. 3, Maret 2021

\title{
ANALISIS PENYINGKAPAN RAHASIA DI BALIK PENDERITAAN AYUB DI DALAM KITAB AYUB
}

\section{Djone Georges Nicolas}

STT IKAT Jakarta, Indonesia

Email: djonealexandrenathanael@gmail.com

\begin{abstract}
This research aims to discover the secret meaning that lies behind Job's suffering in the Book of Job, so that believers in facing various problems do not despair or disappoint with God, but remain grateful and keep waiting for His help. Suffering is not only trying to avoid humans because it is painful, but also because in the midst of the suffering that is experienced, people may be filled with confusion because they do not understand the cause of Allah allowing such suffering. It is a mystery that faced Job in his day and may be a problem for believers today. The author uses descriptive qualitative research with a literature analysis method approach and narrative interpretation by collecting data through biblical sources, books, journals, digital articles, interviews and other documents related to the problem being studied. There are several results as follows: first, Job's suffering represents the suffering that may be experienced by humans in general. Second, Job had an inaccurate heart attitude which led to the wrong response to suffering. The conclusion is that personal knowledge of God is the primary need for humans, because in it are revealed divine secrets which are mysteries to mankind, and the suffering that Allah allows for the purpose of bringing good to His people, namely restoration.
\end{abstract}

Keywords: revelation; secret; job's suffering.

\section{Abstrak}

Penelitian ini bertujuan menemukan makna rahasia yang terdapat di balik penderitaan Ayub di dalam Kitab Ayub, agar orang percaya dalam menghadapi berbagai persoalan tidak putus asa maupun kecewa dengan Allah, melainkan tetap bersyukur dan tetap menantikan pertolongan-Nya. Penderitaan bukan saja coba dihindari manusia oleh karena menyakitkan, tetapi juga karena di tengah penderitaan yang dialami, manusia mungkin dipenuhi kebinggungan oleh karena tidak memahami penyebab Allah mengizinkan penderitaan tersebut. Itu adalah misteri yang dihadapi Ayub pada masanya dan mungkin menjadi suatu persoalan bagi orang-orang percaya di masa kini. Metode penelitian menggunakan kualitatif deskriptif dengan pendekatan metode analisis pustaka dan tafsir narasi dengan pengumpulan data melalui sumber Alkitab, buku-buku, jurnal-jurnal, artikel digital, wawancara dan dokumen lain yang berkaitan dengan masalah yang dikaji. Terdapat beberapa hasil sebagai berikut: pertama, penderitaan Ayub mewakili penderitaan yang mungkin dialami manusia pada umumnya. Kedua, Ayub mempunyai sikap hati yang kurang akurat sehingga menyebabkan respon yang salah dalam menghadapi 
penderitaan. Kesimpulannya adalah bahwa pengenalan akan Allah secara pribadi merupakan kebutuhan utama bagi manusia, sebab di dalamnya tersingkap rahasiarahasia ilahi yang merupakan misteri bagi manusia, dan penderitaan yang diizinkan Allah bertujuan mendatangkan kebaikan bagi umat-Nya, yakni pemulihan.

Kata kunci: penyingkapan; rahasia; penderitaan ayub

\section{Coresponden Author}

Email: djonealexandrenathanael@gmail.com Artikel dengan akses terbuka dibawah lisensi

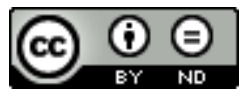

\section{Pendahuluan}

Tidak ada yang terjadi dengan kebetulan di alam semesta ini seperti dipikirkan banyak orang, sehingga mereka menjadi binggung saat mereka dihadapkan dengan penderitaan yang melampaui pengertian mereka. Salah satu kecenderungan manusia adalah hampir selalu berusaha menemukan jawaban melalui pola pikirnya, seolah harus memahami segala sesuatu dan juga menjawab segala pertanyaan, sehingga kehidupan ini dipandang sebagai suatu soal yang perlu dan harus dipecahkan. Namun, faktanya adalah bahwa, banyak pertanyaan yang tidak dapat dijawab oleh manusia sehingga tetap menjadi misteri atau rahasianya Allah Sang sumber, Alfa dan Omega, yang Awal dan yang Akhir.

Berdasarkan data link https://kbbi.web.id/rahasia.html Kamus Besar Bahasa Indonesia, istilah "rahasia" dimaknai sebagai sesuatu yang dengan sengaja disembunyikan dengan tujuan tidak diketahui oleh orang lain, atau sesuatu hal yang belum diketahui maupun sukar dipsaahami. Hal itu menjadi kesusahan tersendiri, apa lagi kalau itu berkaitan dengan rahasia Allah. Maka menurut Dagpo, apabila manusia belum dapat mengetahui maupun mengidentifikasi eksistensinya dengan kebebasan dan berkahnya, manusia itu identik dengan pribadi yang memiliki batu permata namun tidak menyadari akan nilainya yang tinggi (Dagpo Rinpoche, 2020). Terdapat dua tingkatan penderitaan: yaitu penderitaan ringan maupun berat, tergantung anggapan dan respon secara langsung masing-masing orang karena tingkat penderitaan itu relatif, oleh karena penderitaan termasuk realita dalam hidup manusia dan dunia (Mayasari, Chearolina, \& Wang, 2020). Menurut (Hidayat, 2016), pandangan terhadap penderitaan tidak dapat dipersepsikan secara sempit, oleh karena penderitaan merupakan suatu misteri sehingga manusia siapapun dia tidak mengetahui alasan Allah menganugerahkannya (Hidayat, 2016). Menurut (Sardono, Hermiawan, \& Wekin, 2020) dan kawan-kawan dalam penelitian yang mereka telah lakukan, Ayub tetap beriman sehingga mampu memandang dengan positif semua kemalangan dan penderitaan yang menimpanya dan tidak menyalakan Tuhan berdasarkan Ayub 1:1-22 (Eugenius Ervan dkk, 2020). Searah, Kitab Ayub menurut Kalis dan Stefanus membincangkan penderitaan pribadi dan tidak mempersoalkan penderitaan suatu bangsa dalam rangka menunjukkan kedaulatan Allah dalam mengizinkan orang yang takut akan Allah dan tidak bersalah mengalami 
penderitaan, tetapi rela menerimanya dengan mempertahankan imannya (Stevanus \& Marbun, 2019).

Ibu Anita Simamora melalui wawancara Kamis 11 Februari 2021 dengan jujur berkata: "secara manusiawi, saya sulit memahami dan menerima keadilan Tuhan, karena orang yang setia melayani Dia justru lebih banyak kesusahannya dari pada kesukaannya". Menurut (Tanuwidjaja, 2020), di balik peristiwa salib terdapat kemuliaan dan kebangkitan sehingga di balik kesulitan apapun, kemuliaan Allah yang sama sudah dipersiapkan bagi orang yang percaya (Tanuwidjaja, 2020).

Kitab Mazmur 119:17 yang berbunyi: "Bahwa aku tertindas itu baik bagiku, supaya aku belajar ketetapan-ketetapan-Mu”. Penderitaan merupakan salah satu tema yang mungkin selalu terhubung dengan kehidupan manusia dari sejak Adam manusia pertama hingga pada hari ini, sehingga penderitaan apapun model dan tingkatannya harus dihadapi. Isu penderitaan berulang kali menjadi topik bahasan baik dalam Perjanjian Lama maupun Perjanjian Baru, sehingga tidak sedikit orang yang seperti Ayub meresponi dengan salah proses penderitaan sehingga putus asa, kecewa dan bahkan lebih jauh memikirkan untuk mengakhiri hidupnya, oleh karena tidak menangkap kehendak dan rencana Allah yang tersembunyi di balik penderitaan. Mengamati realita yang terjadi saat ini di tengah pandemi Covid-19 yang masih berlanjut dimana penderitaan mungkin dirasakan oleh sebagian besar orang, dibutuhkan buah pikiran dan pandangan Alkitabiah, sebab firman Tuhanlah yang dapat memberi pengertian yang benar tentang penderitaan. Maka, berbeda dengan Eugenius Ervan dkk... dan Kalis Stevanus, penulis melihat sisi lain dari respon Ayub yang tidak sepenuhnya menerima kemalangan yang dialaminya, dan justru karenanya Allah mengizinkan penderitaan dalam rangka mendidik dan membawanya pada tahap pengenalan akan Allah yang lebih mendalam. Sebab, tanpa pengenalan yang benar akan Allah, manusia sulit menerima penderita sebagai suatu kasih karunia, oleh karena hanya di balik pengenalan akan Allah rahasia-rahasia Allah mungkin dapat tersingkap sehingga memerdekakan orang-orang yang menerimanya.

Penelitian terdahulu yang dilakukan oleh (Eugenius Ervan dkk. 2020) yang berjudul Makna Fenomena Kematian Masal di Tengah Pandemi Covid-19 Berdasarkan Refleksi Dari Ayub 1: 11-22, Visio Dei: Jurnal Teologi Kristen dan penelitian (Kalis Stevanus 2019), Memaknai Kisah Ayub Bagi Orang Kristus Dalam Mengalami Penderitaan, Jurnal Teologi Pentakosta. Maka, penulisan ini bertujuan menemukan makna atau rahasia yang terdapat di balik penderitaan Ayub di dalam Kitab Ayub dan juga manfaatnya bagi orang percaya masa kini, sehingga dapat melahirkan respon yang akurat dalam memandang dan menghadapi penderitaan apapun tingkatannya.

Manfaat dari penelitian ini bisa belajar dari penderitaan Ayub yang memberi suatu pelajaran berharga bagi umat Allah pada masa kini, bahwa penyertaan Allah bagi orang percaya adalah pasti, namun penyertaan Allah tidak dimeniadakan masalah dan pergumulan, melainkan memampukan setiap orang yang percaya kepadaNya untuk bertahan dan pada akhirnya menang atas masalah yang dihadapi. 


\section{Metode Penelitian}

Penelitian ini menggunakan penelitian kualitatif deskriptif, dengan pendekatan metode analisis pustaka dan tafsir narasi, dengan pengumpulan data melalui sumber Alkitab, buku-buku, jurnal-jurnal, artikel digital, wawancara dan dokumen lain yang berkaitan dengan masalah yang dikaji. Pendekatan ini digunakan berkaitan dengan ilmu teologi, oleh karena sumber utama yang dianalisa adalah Alkitab dan berbagai sumber pendukung lain (Sonny Eli Zaluchu, 2020). Penulis menggunakan pendekatan pustaka dengan tujuan melihat berbagai pandangan para pakar dan peneliti terkait penderitaan Ayub dan menemukan makna di baliknya, agar dengan demikian dapat memberi pemahaman yang komprehensif secara teologis. Di sisi lain, penulis mengamati realita masa kini dengan menganalisa berbagai pemberitaan yang relevan dan berhubungan dengan penderitaan, tentu atas dasar Alkitab sebagai landasan sentral dalam memberi pemahaman yang dapat diimplementasikan dalam hidup sehari-hari (Katarina \& Darmawan, 2019).

\section{Hasil dan Pembahasan}

\section{Penderitaan Ayub Sebagai Gambaran Umum Penderitaan Manusia}

"Ada seorang laki-laki di tanah Us bernama Ayub; orang itu saleh dan jujur, ia takut akan Allah dan menjauhi kejahatan" (Ayub 1:1). Kendati kualitas Ayub dinyatakan demikian baik dan saleh, Iblis mendapat izin dan kesempatan dari Allah untuk mencobainya. Ayub telah kehilangan segala yang dimilikinya sebagai harta (penderitaan secara ekonomi), ia kehilangan semua anak-anaknya, dan istrinya berbalik melawannya (penderitaan karena duka), penderitaan jasmani oleh karena tubuhnya penuh dengan borok, keluarga dan teman-teman dekatnya salah menilai dan meninggalkannya dan warga kota memandangnya rendah sehingga reputasinya yang baik dan terhormat hancur (penderitaan karena ketidakadilan manusia), secara mental ia dalam kebinggungan yang besar, sangat tertekan secara emosional dimana situasi di sekitarnya tampak seolah tidak ada harapan, dan di atas semuanya secara rohani dia merasa Allah berdiam diri.

Tirza Manaroinsong berpendapat bahwa tidak ada alasan sama sekali yang membuat Ayub layak menerima penderitaan yang dialaminya, karena Allah sendiri yang memujinya (Wawancara Jumat 29 Januari 2021). Manusia ada karena dirancang oleh Allah, diciptakan oleh Allah dan untuk Allah, sebab Allah mempunyai tujuan atas hidupnya. Hanya, banyak orang yang memilih untuk menebak, berteori atau berspekulasi tentang alasan-alasan atau jawaban-jawaban yang mereka butuhkan, tetapi tetap nihil hasil yang diperoleh mereka. Kenapa? Mereka belum memahami sungguh bahwa Allah adalah titik awal dalam hidup manusia dan bahkan sumber kehidupan itu sendiri. Itulah kunci yang diceritakan dalam kisah Ayub. Kelahiran manusia, kematiannya, kota dimana dia tinggal, ras-nya, pasangan hidupnya, suksesnya, penderitaan dsb. tidak ada yang kebetulan. Maka menurut (Tripp, 2018), teologi penderitaan menurut Alkitab dirancang sebagai sarana dengan tujuan pencapaian penghiburan yang 
sebenarnya, arahan yang sebenarnya, perlindungan yang sebenarnya, pertobatan yang sebenarnya, dan harapan yang sesungguhnya. (Heward-Mills, 2015) berkata bahwa penderitaan mempunyai hubungan erat dengan perjanjian di dalam Kristus, sehingga merupakan suatu ketidakwajaran apabila di dalam perjalanan iman penderitaan diabaikan.

\section{Sikap Hati Ayub yang Kurang Akurat}

Beberapa fakta perlu dicermati sehingga melalui ujian dan cobaan yang dialami Ayub, kitab dapat menarik beberapa informasi atau gambaran tentang pribadinya. Ayub mungkin religius dan takut akan Tuhan, dan bahkan menjauhi kejahatan, tetapi Ayub dengan sadar atau tidak sadar memiliki kondisi atau sikap hati yang kurang akurat di hadapan Tuhan. Kondisi atau sikap hati seseorang sulit untuk dideteksi oleh manusia karena posisinya yang di dalam dan tersembunyi, bahkan termasuk pribadi kita sendiri Itu alasan kenapa sahabatsahabatnya Ayub tidak dapat mengoreksi Ayub selama perdebatan mereka yang begitu panjang dan melelahkan bagi mereka (dari pasal 4 - 32). Itulah wilayahnya Tuhan, maka Alkitab mencatat dalam Yeremia 17:9-10 "Betapa liciknya hati, lebih licik dari pada segala sesuatu, hatinya membatu: siapakah yang dapat mengetahuinya? Aku, Tuhan, yang menyelidiki hati, yang menguji batin, untuk memberi balasan kepada setiap orang setimpal dengan tingkah langkahnya, setimpal dengan hasil perbuatannya." Maka Kalis Stevanus berpendapat bahwa pengalaman manusia tentang Allah sangat penting, sebab dibaliknya akan terbentuk suatu pengetahuan yang benar tentang Allah (Kalis, 2019), di dalamnya dapat terungkap banyak hal yang mungkin belum diketahui sebelumnya.

Pertama, Ayub mengasihi Tuhan dan memang berusaha untuk menyenangkan-Nya, tetapi sesungguhnya pada kenyataan Ayub lebih mengasihi anak-anaknya. Ayub 1: 4-5 bunyinya:

"Anak-anaknya yang lelaki biasa mengadakan pesta di rumah mereka masing-masing menurut giliran dan ketiga saudara perempuan mereka diundang untuk makan dan minum bersama-sama mereka. Setiap kali, apabila hari-hari pesta telah berlalu, Ayub memanggil mereka, dan menguduskan mereka; keesokan harinya, pagi-pagi, bangunlah Ayub, lalu mempersembahkan korban bakaran sebanyak jumlah mereka sekalian, sebab pikirnya: 'Mungkin anakanakku sudah berbuat dosa dan telah mengutuki Allah di dalam hati.' Demikianlah dilakukan Ayub senantiasa".

Ayub lebih memilih mempersembahkan korban bakaran untuk penebusan dosa anak-anaknya terus menerus dari pada mendisiplinkan anak-anaknya. Bukankah lebih akurat apabila Ayub mendisiplinkan mereka? Tidak, dia tidak melakukannya sebab mungkin tidak mau menyakiti mereka dengan teguran, sehingga memilih cara yang mudah menyelesaikan masalah. Mungkin dalam pandangannya Tuhan pasti maklum karena kesalehannya. 
Evangelist Alfons Abednego Simanjuntak berpendapat bahwa tidak ada yang jahat yang dilakukan anak-anak Ayub dengan mengadakan pesta (Wawancara Senin 1 Februari 2021). Menurut Fabianus, Ayub merupakan sosok pria yang melaksanakan tugas kepala keluarga dengan baik dan menjadi teladan bagi anak-anaknya sehingga menjadi keluarga bahagia (Eko Fabianus Cindera, 2010). Tetapi perlu diingat bahwa Alkitab tidak mencatat anak-anak Ayub sebagai saleh atau benar, istrinya pun tidak. Bahkan tidak ada satu petunjuk pun dalam kisah di Kitab Ayub yang mengindikasi bahwa anak-anak Ayub satu kali pun berkumpul untuk beribadah kepada Tuhan, tetapi justru indikasi sebaliknya yang kelihatan sehingga perlu dipersembahkan korban oleh ayah mereka terus menerus. Sebagai orang dewasa, seandainya anak-anak Ayub memiliki sisi rohani yang seperti ayah mereka, seharusnya mereka dapat mempersembahkan korban bakaran masing-masing bagi dirinya sendiri. Mereka ada indikasi menjadi anak-anak manja.

Kedua, tanpa sadar kondisi hati Ayub yang tidak akurat memunculkan kesombongan rohani dalam hidupnya. Reputasinya sebagai orang yang saleh dan jujur, takut akan Tuhan dan menjauhi kejahatan, sepertinya memberikan kepada Ayub sebuah otoritas untuk merasa berhak marah terhadap Tuhan ketika ada hal buruk terjadi. Frans Paillin Rumbi katakan bahwa ternyata Ayub salah memahami penderitaan yang dialaminya, padahal Tuhan menggugat hal yang jauh lebih tinggi dari keadilan yang dituntut Ayub (Rumbi, 2019). Ayub 36:1318 berkata bahwa orang fasik mempunyai hati yang menyimpan kemarahan, dan tanpa sadar Ayub menyimpan kemarahan dalam hidup, dan Alkitab menyebut orang yang menyimpan kemarahan sebagai munafik. Itulah kondisi hati Ayub yang membuatnya tanpa sadar merasa berhak berdiri di hadapan Tuhan dan mengatakan bahwa Tuhan telah berlaku tidak adil terhadap dirinya. Perlu goncangan supaya akar dasar kondisi hati Ayub mulai diketahui oleh dirinya sendiri. Penderitaan istri Ayub tidaklah berbeda dengan apa yang dialami Ayub, hanya perbedaanya adalah bahwa istri Ayub mengakui apa yang dirasakannya dengan kehilangan segalan sesuatu yang memberi arti pada kehidupannya, tetapi Ayub menutupi perasaannya (Marie-Claire Barth Frommel (2016:42).

Ketiga, rupanya tanpa sadar, Ayub memiliki kondisi hati yang cenderung mengandalkan kekayaan sebagai jalan keluar dari seluruh masalahnya. Di pasal 1 sudah tercatat bahwa Ayub mempersembahkan korban senantiasa bagi anakanaknya. Untuk persembahkan korban bakaran itu tidak murah, apalagi melakakukannya terus menerus. Butuh lembuh, minimal domba. Tetapi untuk Ayub tidak menjadi masalah sebab dia adalah orang yang berlimpah-limpah kekayaan. Kambing dombanya ribuan, sehingga tanpa sadar dia mencoba menyuap Tuhan (Ayub 36: 16-21 Terjemahan The Message Bible). Allah lebih menghendaki hati Ayub dan anak-anak Ayub daripada korban bakaran terus menerus. 
Keempat, Ayub ternyata memiliki pengenalan akan Tuhan yang tidak seimbang. Dia hidup hanya dari kata orang:

"Maka jawab Ayub kepada Tuhan: aku tahu, bahwa Engkau sanggup melakukan segala sesuatu, dan tidak ada rencana-Mu yang gagal. Firman-Mu: Siapakah dia yang menyelubungi keputusan tanpa pengetahuan? Itulah sebabnya, tanpa pengertian aku telah bercerita tentang hal-hal yang sangat ajaib bagiku dan yang tidak kuketahui. FirmanMu: Dengarlah, maka Akulah yang akan berfirman; Aku akan menanyai engkau, supaya engkau memberitahu Aku. Hanya dari kata orang saja aku mendengar tentang Engkau, tetapi sekarang mataku sendiri memandang Engkau. Oleh sebab itu aku mencabut perkataanku dan dengan menyesal aku duduk dalam debu dan abu." (Ayub 42:1-6).

Karena Ayub hanya mengenal Tuhan dari kata orang, di saat bencana datang pertama kali, Ayub berkata bahwa Tuhan yang telah memberi dan Dia juga yang mengambil kembali, lalu ia memuji nama Tuhan (Ayub 1:21). Perkataan Ayub walaupun kedengaran rohani, adalah kurang akurat. Karena Tuhan tidak pernah mengambil, Tuhan mungkin meminta tetapi tidak mengambil. Sebab kata 'mengambil' mempunyai makna atau arti memaksa, dan itu yang sesungguhnya yang Ayub rasakan dengan semua kejadian yang telah menimpa dirinya dalam sehari itu. Seolah dirampas semua yang berharga yang dia miliki begitu saja.

Di sisi lain, ketika istrinya meminta Ayub menyangkali dan kutuki Tuhan dan mati, Ayub berkata: "Engkau berbicara seperti perempuan gila! Apakah kita mau menerima yang baik dari Allah, tetapi tidak mau menerima yang buruk?" (Ayub 2: 10). Memang Alkitab berkata selanjutnya bahwa Ayub tidak berbuat dosa dengan bibirnya, yang artinya Ayub tidak mengucapkan kata-kata yang melawan Tuhan, tetapi kondisi hatinya yang didasari oleh pengenalan akan Tuhan yang tidak sehat dan akurat, membuat dia berkata dan meyakini bahwa kalau ada sesuatu yang baik itu datang dari Tuhan, tetapi sebaliknya ia juga meyakini bahwa yang buruk datang dari pada Tuhan juga.

Mungkinkah ada sesuatu yang buruk dari pada Tuhan? Timothy (Christianto, Suria, \& Tafonao, 2020) berkata bahwa penderitaan merupakan sarana perpindahan dari pengetahuan akan Allah yang abstrak pada perjumpaan pribadi yang lebih mendalam sebagai sumber kehidupan. Iblislah si pencuri yang datang mencuri, membunuh dan membinasakan; tujuan Tuhan adalah agar manusia mempunyai hidup dalam segala kelimpahan (Yoh. 10:10). Tuhan tidak pernah memberi yang buruk. Sebagai akibat pengenalan akan Tuhan yang tidak seimbang, Ayub saat hal yang buruk datang, memunculkan kepahitan terhadap Tuhan. Ayub 6: 4-9 berbunyi:

"Karena anak panah dari yang Mahakuasa tertancap pada tubuhku, dan racun-nya diisap oleh jiwaku; kedasyatan Allah seperti pasukan melawan aku. Meringkikkah keledai liar di tempat rumput muda, atau melenguhkah lembuh dekat makanannya? Dapatkah makanan tawar dimakan tanpa garam atau apakah 
putih telur ada rasanya? Aku tidak sudi menjamahnya, semuanya itu makanan yang memualkan bagiku. Ah, kiranya terkabul permintaanku dan Allah memberi apa yang aku harapkan! Kiranya Allah berkenan meremukkan aku, kiranya Ia melepaskan tanganNya dan menghabisi nyawaku!".

Ayub menganggap semua yang buruk yang dialaminya merupakan rekayasa tangan Tuhan untuk menghancurkan hidupnya. Oleh karena ketidak akuratan-nya dalam pengenalan akan Tuhan. Allah yang kita sembah adalah Allah yang baik, dan tidak pernah merancang hal yang buruk bagi kita. Terpikir atau tersirat pun tidak pernah dalam pikiranNya, karena Dia adalah Bapa yang baik. Alkitab menyatakan dengan jelas dalam ibrani bahwa walaupun ganjaran itu diterima, akan menghasilkan buah kebenaran. Dalam Ayub 10: 1-22 pun kita lihat keluhan Ayub yang begitu menuduh Allah menikmati menyiksa dirinya dan menganggap dirinya tidak layak menerima semua yang dialaminya. Tuhan bagi Ayub dahulu adalah baik tetapi sekarang adalah jahat. Ketidakseimbangan dalam pengenalan akan Tuhan membuat Ayub mencurigai Tuhan.

Kelima, tanpa sadar Ayub memiliki dalam hatinya godaan untuk menjalani hidup seperti orang-orang fasik. Dia berpendapat bahwa nasib orang yang hidup takut akan Tuhan sia-sia dan tanpa jaminan, dan justru bahwa sebaliknya orangorang fasik lebih baik nasib mereka. Ayub 34: 5-10 mencatat:

"Karena Ayub berkata: aku benar, tetapi Allah mengambil hakku; kendati aku mempunyai hak aku dianggap berdusta, sekalipun aku tidak melakukan pelanggaran, lukaku tidak dapat sembuh lagi. Siapakah seperti Ayub, yang minum hujatan terhadap Allah seperti air, yang mencari persekutuan dengan orang-orang yang melakukan kejahatan dan bergaul dengan orang-orang fasik? Karena dia telah berkata: tidak berguna bagi manusia, kalau ia dikenan Allah. Oleh sebab itu, kamu orang-orang berakal budi, dengarkanlah aku: Jauhlah dari pada Allah untuk melakukan kefasikan, dan dari yang Maha kuasa untuk berbuat curang."

Selama ini bagi Ayub Allah tampak begitu dekat selama semuanya berjalan lancar dalam keluarganya, usaha-usahanya, kesehatan-nya, hubungan dengan orang sekitarnya, status sosialnya. Tetapi setelah segala sesuatu lenyap, Ayub mengalami tekanan yang sangat dasyat yang mengakibatkan secara emosional Ayub goncang dan mendekat kepada batas kesabarannya. Memang rasa sakit yang dialami Ayub karena kesedihan atas kematian anak-anaknya, kebangkrutannya, dan luka-lukanya punya pengaruh besar dalam penderitaan emosional yang dialaminya, tetapi ada tiga faktor yang lain yang memperberat keadaannya sehingga dia putus asa dan hancur hati sehingga dia menyesali hari kelahirannya (Ayub 3:1-10), mengharapkan mati ketika dilahirkan (Ayub 3:1119) dan ingin mati saat itu (Ayub 3:20-26).

Di tengah penderitaan seperti yang Ayub alami, keluhan dan kebimbangan sangatlah wajar. Namun melalui kisah Ayub kita dapat memahami dan menyadari bahwa kesalehan seseorang belum tentu menjamin respon yang benar 
di dalam menghadapi proses penderitaan dan Ayub merupakan salah satu contoh. Oleh karena itu Allah lebih menghendaki pengenalan akan Allah melalui hubungan pribadi, sebab melaluinya terdapat penyingkapan maksud Allah yang dalam (rahasia) yang memampukan seseorang meresponi apapun yang Tuhan izinkan dengan benar dan akurat. Dengan demikian orang-orang yang menderita dapat tetap memposisikan diri sebagai ciptaan dan tidak menuntut pertanggungjawaban Sang Pencipta Maha Agung atas segala penderitaan yang dialami dan belum dimengerti alasannya.

Maka jika dikorelasikan dengan kehidupan manusia termasuk orang percaya saat ini di tengah pandemi Covid-19 yang sudah hampir setahun berlangsung, dan tidak ada yang tahu kapan akan berakhirnya, yang berdampak luas di dalam segala aspek kehidupan manusia, dan juga memberi dampak yang kurang baik bagi orang percaya dalam menjalankan ibadahnya (Dewi Sartika, Irene Silviani, 2020), juga berdampak di dalam elemen sosial politik maupun ekonomi dan mengakibatkan guncangan secara psikologis sehingga sejumlah besar orang mengalami kepanikan, frustrasi hingga kematian. (Abdon Amtiran, 2020), orang-orang percaya dipanggil untuk tetap tegar, bersandar dan berserah sepenuhnya kepada Allah yang punya kendali atas segala sesuatu, selalu mengucap syukur kepada Allah sebagai bukti iman di tengah proses ujian dan penderitaan yang dialami apapun bentuk, sebab itulah yang berkenan kepada Allah, sebab apa bila Allah diam, tidak bisa diartikan sepertinya Allah tidak mau atau tidak mampu menolong umat-Nya, melainkan melalui iman, orang percaya tetap menaruh kepercayaan kepada Allah sampai segala sesuatunya menjadi indah sesuai maksud Allah bagi kebaikan umat-Nya (Arif Wicaksono, 2018). Penderitaan Ayub dapat memberi suatu pelajaran yang berharga bagi umat Allah pada masa kini, bahwa penyertaan Allah bagi orang percaya adalah pasti, namun penyertaan Allah dimeniadakan masalah dan pergumulan, melainkan memampukan setiap orang yang percaya kepadaNya untuk bertahan dan pada akhirnya menang atas masalah yang dihadapi. Oleh karena ada batas-batas yang Allah tetapkan di tengah proses penderitaan yang dialami Ayub, sehingga memberi pengajaran bahwa jika Allah membiarkan umat-Nya mengalami penderitaan, itu tetap di dalam kendaliNya (Marsi Bombongan, 2020).

\section{Kesimpulan}

Pengenalan akan Allah secara pribadi merupakan kehendak Allah dan kebutuhan utama bagi manusia, sebab di dalamnya tersingkap rahasia-rahasia ilahi yang merupakan misteri bagi manusia, dan penderitaan yang diizinkan Allah bertujuan mendatangkan kebaikan bagi umat-Nya, yakni pemulihan sejati. Respon yang benar di tengah penderitaan bersumber dari pengenalan yang benar akan Allah, dan itulah yang disebut beriman. Maka, orang-orang percaya dipanggil untuk belajar mempercayai Tuhan walaupun di tengah kegelapan yang paling gelap, sekalipun tidak mengerti, sebab iman merupakan kasih karunia anugerah Allah bagi manusia agar mampu 
Djone Georges Nicolas

menerima ketidakpastian. Maka, di tengah pandemi Covid-19 yang sudah hampir setahun berlangsung dan tidak ada yang tahu kapan akan berakhirnya, orang percaya harus tetap tegar dan penuh pengharapan di tengah proses ujian dan pergumulan hidup, sebab itulah yang berkenan kepada Allah. 


\section{BIBLIOGRAFI}

Amtiran, Abdon (2020). Pandemi Covid-19 dan Implikasinya Terhadap Polarisasi Mazhab Teologi di Indonesia, Magnum Opus Jurnal Teologi dan Kepemimpinan Kristen, 1(2), 64-71.

Bombongan, Marsi, Rantesalu (2020). Penderitaan dari Sudut Pandang Teologi Injili, Jurnal Ilmiah Religiosity Entity Humanity (JIREH), 2(2), 126-135.

Christianto, Victor, Suria, Isak, \& Tafonao, Talizaro. (2020). Religiositas, olahraga dan etika belaskasih (hesed): Religiosity, sports and the ethics of mercy (hesed). Jurnal Teologi Amreta (ISSN: 2599-3100), 3(2).

Eko Fabianus Cindera. (2010). Eko Fabianus Cindera, 2021. Ayub di Lembah Corona, Surabaya: Cipta Media Nusantara.

Heward-Mills, Dag. (2015). The art of leadership. English: Dag Heward-Mills.

Hidayat, Elvin Atmaja. (2016). Iman Di Tengah Penderitaan: Suatu Inspirasi TeologisBiblis Kristiani. Melintas, 32(3), 285-308.

Katarina, Katarina, \& Darmawan, I. Putu Ayub. (2019). Implikasi Alkitab dalam Formasi Rohani pada Era Reformasi Gereja. Epigraphe: Jurnal Teologi dan Pelayanan Kristiani, 3(2), 81-93.

Mayasari, Iis Dahlia, Chearolina, Chearolina, \& Wang, Suryowati. (2020). Pendidikan Penderitaan Dalam Kitab Ayub Guna Memberi Solusi Perkara-Perkara Dunia Pelayan Tuhan. Excelsis Deo: Jurnal Teologi, Misiologi, dan Pendidikan, 4(2), 59-70.

Rumbi, Frans Paillin. (2019). Babak Akhir Penderitaan, Dosa Dan Teodice Dalam Epilog Kitab Ayub 42: 7-17. Veritas Lux Mea (Jurnal Teologi dan Pendidikan Kristen), 1(2), 53-64.

Sardono, Eugenius Ervan, Hermiawan, Nikodemus, \& Wekin, Oktavianus Klido. (2020). Makna Fenomena Kematian Massal di Tengah Pandemi Covid-19 Berdasarkan Refleksi dari Ayub 1: 1-22. Visio Dei: Jurnal Teologi Kristen, 2(2), 265-283.

Sartika Dewi Butar-butar, Irene Silviani (2020). Komunikasi Krisis di Tengah Pandemi Covid-19 GBI Pondok Toba Deli Serdang, Jurnal Massage Komunikasi, 9(1), 1-5.

Stevanus, Kalis, \& Marbun, Stefanus. (2019). Memaknai Kisah Ayub Bagi Orang Kristen Dalam Menghadapi Penderitaan. LOGIA: Jurnal Teologi Pentakosta, 1(1), $25-43$.

Tanuwidjaja, Sundoro. (2020). Pentingnya Kesulitan dan Penderitaan: Menemukan Nilai dan Makna Kehidupan dalam Perspektif Iman Kristen. Sola Scriptura: Jurnal 
Djone Georges Nicolas

Teologi, 1(1), 53-72.

Tripp, Paul David. (2018). Sex in a broken world: How Christ redeems what sin distorts. Crossway.

Wicaksono, Arif (2018). Ketika Allah "Diam": Analisis Retorika Ayub 39:4-15, Evangelikal: Jurnal Teologi Injili dan Pembinaan Warga Jemaat, Ketika Allah "Diam": Analisis Retorika Ayub 39:4-15. Journal Sttsimpson 2(2), 135-146. 